\title{
Täglich Bewegung hält Diabetes in Schach
}

Fragestellung: Welche Rolle spielt tägliche körperliche Aktivität bei der Prävention eines Diabetes mellitus Typ 2 oder in der Behandlung eines neu diagnostizierten Typ-2-Diabetes?

Hintergrund: Es ist bekannt, dass tägliche körperliche Aktivität invers mit metabolischen Risikofaktoren, Typ-2-Diabetes und einer Vielzahl anderen Erkrankungen korreliert. Meist wird ein tägliches Schritteziel von 10000 Schritten empfohlen. Studien zeigen allerdings auch schon, dass jeder Block von 2000 Schritten das kardiovaskuläre Risiko um 14\% reduziert, andere Studien ergaben, dass regelmäßige Alltagsaktivität den Blutdruck signifikant senken kann und sogar bei eineiigen Zwillingen das Risiko zum Auftreten einer Demenz um 58\% und einer Depression um mehr als 50\% senkt. Interessant ist allerdings die Frage, wie sehr mangelnde Alltagsaktivität als Risikofaktor gesehen werden kann und v.a., welche Rolle geringe Alltagsaktivität für die Entwicklung eines Prädiabetes oder Diabetes mellitus spielt. Dieser Frage gingen die Au-

Originalie

Hamasaki H, Noda M, Moriyama $\mathrm{S}$ et al. Daily Physical Activity Assessed by a Triaxial Accelerometer Is Beneficially Associated with Waist Circumference, Serum Triglycerides, and Insulin Resistance in Japanese Patients with Prediabetes or Untreated Early Type 2 Diabetes. J Diabetes Res. 2015;2015:526201. toren in der folgenden japanischen Studie nach.

\section{Patienten und Methoden: Es} wurden 80 japanische $\mathrm{Pa}$ tienten untersucht, die eine gestörte Glukosetoleranz hatten, aber noch keinen diagnostizierten Diabetes oder eine Medikation hinsichtlich eines Diabetes mellitus oder
Lipidstoffwechsels. Im Rahmen dieser Beobachtungsstudie erhielten sie einen dreidimensionalen Akzelerometer. Der Zusammenhang zwischen körperlicher Aktivität pro Tag und Taillenumfang, Blutdruck, Nüchternglukose, Serumtriglyzeriden, Insulin und auch Insulinresistenz wurde analysiert.

Ergebnisse: Nach Adjustierung von Alter und BMI ist der Grad körperlicher Alltagsaktivität umgekehrt assoziiert mit Taillenumfang, Nüchternserum-Triglyzeriden und Seruminsulin. Bei Männern kam noch eine Assoziation mit reduziertem systolischem Blutdruck und verbesserten Werten für Nüchternglukose und Insulinresistenz insgesamt dazu. Überraschenderweise konnte man keinen signifikanten Zusammenhang zwischen mehr Alltagsaktivität und metabolischen Risikofaktoren bei Frauen finden.

Schlussfolgerung: Alltagsaktivität wirkt positiv auf Taillenumfang, Serumtriglyzeride und Insulinresistenz bei Prädiabetes oder unbehandeltem Typ-2-Diabetes.
Bei japanischen Männern hat die vermehrte Bewegung am besten gewirkt, bei anderen Völkern wird es aber ähnlich sein.

\section{- Kommentar von Prof. Dr. med. Peter Schwarz}

\section{Stellen die Wechseljahre Frauen ein Bein?}

Interessant! Der Studie zufolge scheint es so zu sein, dass körperliche Alltagsaktivität bei Frauen einen geringeren Effekt hat als bei Männern. Ist das wirklich so und kann man das so glauben?

Zunächst zeigt die Studie, dass körperliche Alltagsaktivität, unabhängig vom Erreichen eines Ziels von 10000 Schritte pro Tag, günstig mit der Reduktion von metabolischen Risikofaktoren wie Glukosetriglyzeriden und Insulinresistenz assoziiert ist. Der Effekt war nachhaltig und substanziell. Bei Frauen war allerdings bei vielen weiteren metabolischen Risikofaktoren kein Zusammenhang zu sehen. Die Autoren erklären das einerseits mit dem Alter der Frauen in der Studie (um die 60 Jahre), sodass die Frauen postmenopausal waren und verstärkt Muskelabbau und Sarkopenie vorlag. Ein anderes Argument könnte auch das sich verändernde Fettverteilungsmuster postmenopausal darstellen, wobei die Frau zu dem Zeitpunkt stärker eine viszerale Adipositas akkumuliert als ein Mann, der das schon über viele Jahre durchmacht. Das sind hypotheti- sche Erklärungen und sicher spielen auch noch Unterschiede zwischen kaukasischer Bevölkerung und asiatisch/japanischer Bevölkerung dabei eine Rolle. Die bemerkenswerte Quintessenz aber dabei ist: Körperliche Alltagsaktivität ist, egal auf welchem Niveau, mit einer Reduktion von Risikofaktoren für Prädiabetes und Diabetes mellitus assoziiert und damit eines der Erfolgsmodelle für eine nachhaltig Diabetesprävention.

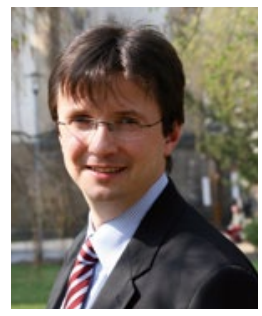

Prof. Dr. med. Peter Schwarz

Department of Medicine III

Prevention and Care of Diabetes

University of Dresden

Fetscherstr. 74

01307 Dresden

peter.schwarz@uniklinikum-dresden.de 